\title{
MODELLING AND FORECASTING STOCK MARKET VOLATILITY OF NASDAQ COMPOSITE INDEX
}

\author{
I Wayan Sunarya \\ STMIK STIKOM Denpasar, Bali, Indonesia \\ iwayansunarya@gmail.com
}

\begin{abstract}
On the NASDAQ Composite Index from March 1971 to April 2019 it appears that the data is not stationary. For this reason, differentiation is needed by finding the value of stock returns from the NASDAQ Composite Index data from March 1971 to April 2019.. The ARIMA model (8,0,6) was chosen because it has the smallest AIC value of 12,664073. This can be used as a reference later that the ARIMA model $(8.0,6)$ is the best model in conducting forecasting. After that, the GARCH model is continued which aims to determine the ARIMA-GARCH model combination model. From the results of the analysis, it is known that the best model for forecasting the return value of the NASDAQ Composite Index is a combination of ARIMA (8.0,6)-EGARCH $(1,1)$ models, which from the results of this analysis are known for fluctuating return values and index values for NASDAQ for one year in the future it is stagnant and does not show a trend.
\end{abstract}

Keywords: ARCH; ARIMA; GARCH; NASDAQ; Stock

\section{INTRODUCTION}

The NASDAQ stock market ordinarily known as NASDAQ was established in 1971 by the National Association of Securities Dealers (NASD) as the world's first electronic financial exchange pointing the decrease of wasteful individual to-individual stock exchanges and making a progressively straightforward and quicker framework. Toward the starting it was just a citation framework, which went live for 2,500 over the counter securities (Isida Mansaku, Saimir Mansaku, 2016). NASDAQ considered as a standout amongst the most significant securities exchanges on the planet, both in the promoted exchanged that common or by the hatching of such organizations, particularly if those organizations are fascinating in mechanical angles just as these organizations are exemplified with worldwide ones out of United states. In addition, NASDAQ assumed an incredible job when the worldwide financing emergency (Neama, 2016). Surely understood as a "dread record" for resource markets, it reflects both securities exchange vulnerability (the "physical" anticipated unpredictability), and a change chance premium, which is additionally the normal premium from selling financial exchange difference in a swap contract (Bekaert \& Hoerova, 2014). For volatility of NASDAQ Composite from March 1971 until April 2019 can be seen in figure 1 below: 


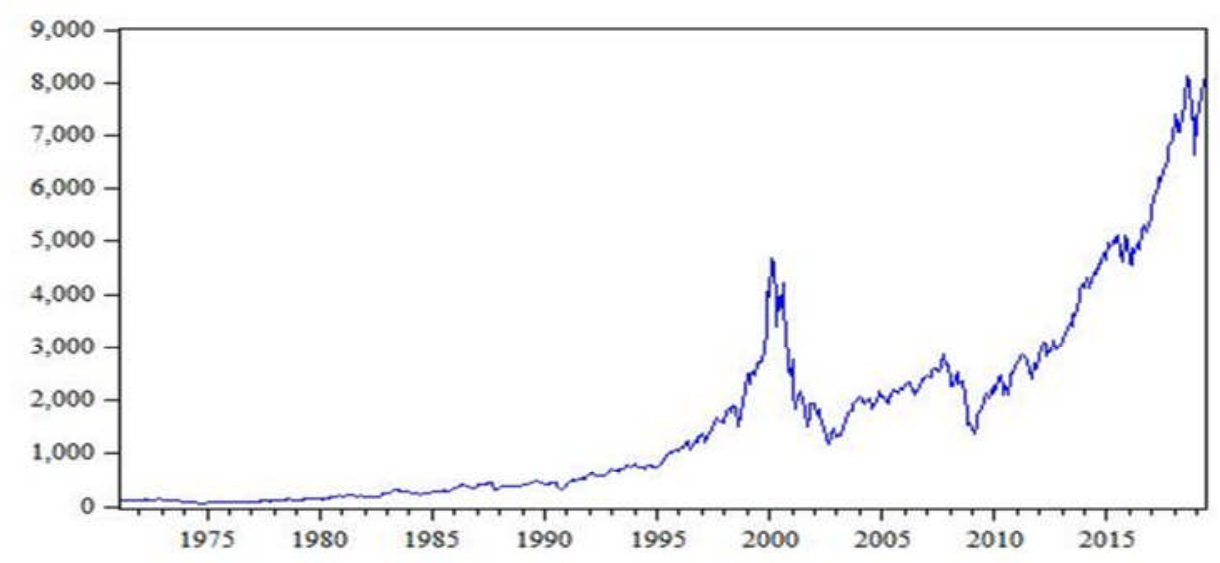

Figure 1. The NASDAQ Composite Index Source: Yahoo Finance

\section{LITERATURE REVIEW}

Lin (2018) broadened the variables influencing the contingent fluctuation to two angles: the mean square mistake and restrictive difference of past periods, and built up the GARCH model. Based on the two models referenced over, the scientists found the nearness of topsy-turvy data marvel in the vacillations of money related time arrangement, to be specific the variances causing by the terrible news are in every case a lot more noteworthy than the uplifting news. And this phenomenon is also proved by the study of Hung (2011) and Katsiampa (2017) examined GARCH model to adaptively gauge financial exchange instability where the outcome for reproduction show that the proposed strategy offers huge enhancements in estimating execution. And this phenomenon is also proved by the study of Caporin and Costola, (2019), Lin (2018), Hartaty, Jasanta and Harjum (2018) contemplated the securities exchange, and they connected the EGARCH, AGARCH, NGARCH, VGARCH and GJRGARCH model all the while in the exploration, proposing the idea of news effect bend. In addition, they found by exact examination that the securities exchange for sure existed instability asymmetry. What's more, the restrictive change assessed by EGARCH model were commonly bigger than different models, yet in the impression of the GJR-GARCH model did the best. Lahmiri and Boukadoum (2014) found in evaluating the day by day information of S\&P 500 Index from 2011, February 28th to March eleventh, EGARCH $(2,1)$ model performed superior to ARCH (5), GARCH $(1,2)$ and IGARCH $(1$, $1,0)$. His outcomes likewise demonstrate that EGARCH model is better than the straightforward SV model which uses the greatest probability to do estimation. Monfared \& Enke (2014) utilized GARCH family models to appraise the NASDAQ Composite from $1 / 8 / 1997$ to $9 / 1 / 2011$, finding that negative stuns influence lopsidedly on the every day return arrangement. Alemohammad, Rezakhah, \& Alizadeh (2018) applying the log return of some piece of S\&P 500 records so that can be demonstrate the contending execution of in test fit and out of test conjecture unpredictability and incentive in danger of the proposed model. 


\section{RESEARCH METHOD}

\subsection{ARCH Model}

The motivation behind this work is to think about an augmentation of the ARCH procedure which can catch the vacillation of the intra-day cost and the liquidity existent in the market (Bahamonde, Torres, \& Tudor, 2018). Lin (2018) have contention its change is the straight blend of the square of constrained commotion esteems previously (reflects autoregression), and it is a period fluctuating sum (reflects contingent heteroscedasticity). Bahamonde et al. (2018) present variation of the ARCH model with the fragmentary Brownian movement developments and examine its reliance structure. Lin (2018) ARCH model has a basic form as follows:

$$
\begin{aligned}
r_{t} & =f\left(t, r_{t-1}, r_{t-2}, \ldots\right)+\varepsilon_{t} \\
\varepsilon_{t} & =\sqrt{h_{t} e_{t}} \\
h_{t} & =\omega+\sum_{j=1}^{q} \lambda_{j} \varepsilon_{t-j}^{2}
\end{aligned}
$$

\subsection{Symmetric GARCH model}

Basically, the GARCH procedures are parametric models that expect a direct relationship structure in the information (Lahmiri \& Boukadoum, 2014). To address the current issues in ARCH model, Lin (2018) broadened it by adding an autoregressive term to get the GARCH model. The least difficult GARCH model is the GARCH $(1,1)$ :

$$
R_{t}=a_{0}+a_{1} R_{t-1}+\varepsilon_{t}
$$

\section{RESULT AND DISCUSSION}

\section{Result}

To better ensure the data in figure 1 is stationary or not, there needs to be a test called the unit root test. The results of the unit root test using EViews 10 software, from NASDAQ data that have not experienced differentiation as follows:

$$
\begin{aligned}
& \varepsilon_{t}=i i d N\left(0, \sigma_{t}^{2}\right) \\
& \sigma_{t}^{2}=\alpha_{0}+\alpha_{1} \varepsilon_{t-1}^{2}+\beta_{1} \sigma_{t-j}^{2}
\end{aligned}
$$

\subsection{EGARCH Model}

The EGARCH model was created to take into consideration deviated impacts among positive and negative stuns on the restrictive change of future perceptions (Lama et al., 2015). Lin (2018) proposed Exponential GARCH model, in particular EGARCH model, on premise of the GARCH model, he improved the model to:

$$
\begin{aligned}
& R_{t}=\beta_{0}+\beta_{1} R_{t-1}+\varepsilon_{t} \\
& \ln \left(\sigma_{t}^{2}\right)=\alpha_{0}+\sum_{i=1}^{q}\left(\alpha_{i}\left|\frac{\varepsilon_{t-i}}{\sigma_{t-i}}\right|+\gamma_{i}\left(\frac{\varepsilon_{t-i}}{\sigma_{t-i}}\right)\right)+\sum_{j=1}^{p}\left(\beta_{j} \ln \sigma_{t-j}^{2}\right)
\end{aligned}
$$

\subsection{The steps technique data analysis}

The analysis technique used in applying the GARCH model in this study uses the help of EViews 10 software program with the following sequence of steps (Eliyawati, Hidayat, \& Azizah, 2014) :

1. Data Stationarity Test

a. Stationarity Test

b. Differentiation Process

2. Identification of the ARIMA Model

3. Estimation of the ARIMA Model

\begin{tabular}{|c|c|}
\hline \multicolumn{2}{|c|}{ ADF test statistic } \\
\hline t-Statistic & Prob \\
\hline 1,970554 & 0,9999 \\
\hline
\end{tabular}

4. ARIMA Model Diagnosis Test

5. Identification of ARCH-GARCH

(Heteroscedasticity) effects

6. Estimated GARCH model

7. Evaluate the model

8. Forecasting

Table 1. Unit Root Test before difference

From the data in table 1 it can be seen that the value of p-value Augmented DickeyFuller is 0.9999 greater than the value of $\alpha=$ 0,05 , so it can be made an analysis that the data in figure two is not stationary. 
The next step is to make NASDAQ data from March 1971 to April 2019 stationary, so data differentiation must be done by finding the value of the stock market return using the formula (Lin, 2018) :

$\mathrm{Ri}=\ln (\mathrm{Pi} / \mathrm{Pi}-1)$

Where $\mathrm{Pi}$ is the daily closing index of NASDAQ composite index at days $\mathrm{t}$, and $\mathrm{Pi}-$ $t$ is the index at days $t-1$. By using the formula of stock market return in formula no.12, the process of transforming data using EViews 10 software will be as follows:

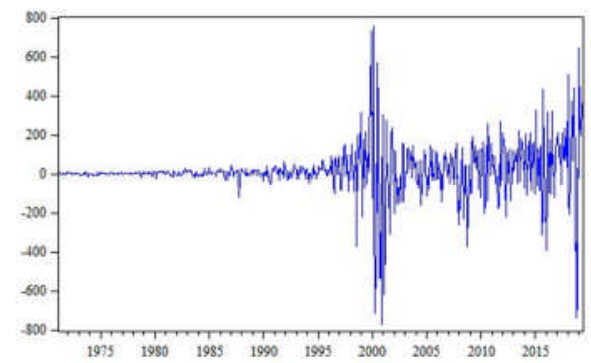

Figure 2. The Return NASDAQ

Source : Figure 1 (Data Processed)

Then from the data in figure 3 a unit root test is performed using EViews 10 software, where the results are as follows:

Table 2. Unit Root Test after difference

\begin{tabular}{|cc|}
\hline \multicolumn{2}{|c|}{ ADF test statistic } \\
t-Statistic & Prob \\
$-6,227772$ & 0,0000 \\
\hline Source : Figure 2 & (Data Processed)
\end{tabular}

From the data in table two, it can be seen that the Augmented Dickey-Fuller pvalue value of 0,000 is smaller than the value

Table 3. Determination ARIMA Model

\begin{tabular}{|ccccc|}
\hline Model & LogL & AIC* & BIC & HQ \\
$(8,0,6)$ & $-3637,59$ & 12,66 & 12,79 & 12,71 \\
\hline
\end{tabular}

Source : Figure 3 (Data Processed)

From the data in table 3 , it can be seen that the ARIMA model $(8,0,6)$ is the best model because it has the smallest Akaike Info Criterion (AIC) value of 12,66. After getting the best ARIMA model, the ARIMA model $(8,0,6)$, followed by determining the ARCH, GARCH, TARCH and EGARCH models $\alpha=0,05$, so that analysis can be made that the data in figure two is stationary.

To determine the lag that will be the determinant of the formation of the ARIMA model, the analysis of the AutoCorrelation Function (ACF) and Partial AutoCorrelation Function (PACF) is used using EViews 10 software, where the results are as follows:

\begin{tabular}{|c|c|c|c|c|c|c|}
\hline Autocorrelation & Partial Correlation & & $\mathrm{AC}$ & PAC & Q-Stat & Prob \\
\hline 11 & 11 & 1 & 0.022 & 0.022 & 0.2732 & 0.601 \\
\hline in & il & 2 & 0.038 & 0.038 & 1.1309 & 0.568 \\
\hline 101 & 101 & 3 & -0.033 & -0.035 & 1.7691 & 0.622 \\
\hline 14 & 101 & 4 & -0.041 & -0.041 & 2.7519 & 0.600 \\
\hline 11 & 11 & 5 & -0.019 & -0.015 & 2.9674 & 0.705 \\
\hline in & 问 & 6 & 0.105 & 0.109 & 9.4527 & 0.150 \\
\hline 111 & ili & 7 & 0.049 & 0.044 & 10.851 & 0.145 \\
\hline 19 & 11 & 8 & 0.108 & 0.096 & 17.686 & 0.024 \\
\hline 11 & 11 & 9 & -0.023 & -0.026 & 17.996 & 0.035 \\
\hline 1] & 的 & 10 & 0.090 & 0.097 & 22.789 & 0.012 \\
\hline 11 & 11 & 11 & -0.022 & -0.011 & 23.084 & 0.017 \\
\hline 101 & di & 12 & -0.061 & -0.071 & 25.289 & 0.014 \\
\hline
\end{tabular}

Figure 3. ACF \& PACF Analysis Source : Figure 2 (Data Processed)

From figure 3, it is clear that the lags 6, 8 and 10 pass the Confidence Bounds line so that the ACF and PACF analysis can be concluded that lags $6,8,10$ can be used to create ARIMA models. After making an ACF and PACF analysis on the NASDAQ Composite Index return data, it is continued to determine the best ARIMA model that will be used later to form the GARCH model where the best model is ARIMA $(8,0,6)$. For the value ARIMA $(8,0,6)$ can be seen as follow:

where the best results are seen from the smallest Akaike Info Criterion (AIC) value.

Table 4. Result Akaike Info Criterion (AIC)

\begin{tabular}{|c|c|c|}
\hline No. & Model & AIC Value \\
\hline 1. & ARIMA $\quad(8,0,6)-$ & 11,99151 \\
\hline 2. & ARIMA $\quad(8,0,6)$ & 10,49955 \\
\hline 3. & ÄRIMA $\quad(8,0,6)$ & 10,47681 \\
\hline 4. & $\bar{A}$ ATIMA $\quad(8,0,6)-$ & 10,47331 \\
\hline
\end{tabular}

Source : Figure 3 (Data Processed) 
From the results of the analysis in table 4 , it is known that in the ARIMA $(8,0,6)$ EGARCH $(1,1)$ model the lowest AIC value is 10,47331 . From table four, it can be seen that the ARIMA $(8,0,6)$ - EGARCH $(1,1)$ model is the best model but it is necessary to do more testing, namely the autocorrelation test. From the results of the ARIMA $(8,0,6)$ EGARCH $(1,1)$ model after processing the data with Eviews 10 software get the following results:

\begin{tabular}{|c|c|c|c|c|c|}
\hline Autocorrelation & Partial Correlation & $\mathrm{AC}$ & PAC & Q-Stat & Prob* \\
\hline ओ & 山1 & $1-0.020$ & -0.020 & 0.2216 & 0.638 \\
\hline 11 & 11 & 20.029 & 0.028 & 0.6899 & 0.708 \\
\hline $1 \mid 1$ & 11 & 30.001 & 0.002 & 0.6907 & 0.875 \\
\hline 11 & 11 & $4-0.002$ & -0.002 & 0.6923 & 0.952 \\
\hline$\| 1$ & 11 & $5-0.003$ & -0.003 & 0.6975 & 0.983 \\
\hline $1 / 1$ & $1 \mid 1$ & $\begin{array}{ll}6 & 0.003\end{array}$ & 0.003 & 0.7035 & 0.994 \\
\hline 山 & 11 & $7-0.026$ & -0.026 & 1.0986 & 0.993 \\
\hline 11 & 11 & $8-0.023$ & -0.024 & 1.4048 & 0.994 \\
\hline
\end{tabular}

Figure 4. ACF \& PACF Analysis in ARIMA (8, 0, 6) - EGARCH $(1,1)$ Model

Source : Table 5 (Data Processed)

From table 4, it is clear that all lags do not cross the Confidence Bounds line and the p- value is greater than $\alpha=0.05$ so that from the $\mathrm{ACF}$ and PACF analysis in table five, it can be concluded that the ARIMA model $(8,0,6)$ EGARCH $(1,1)$ is free from AutoCorrelation. In table 4 the ARCH Effect test can be carried out, where the results can be seen as follows:

Table 7. ARCH Effect Test

\begin{tabular}{|ll|}
\hline Heteroskedasticity Test: & ARCH \\
F-Statistic & Prob. F(1,566) \\
0,219521 & 0,6396 \\
& \\
Obs*R-squared & Prob. Chi-Square(1) \\
0,220211 & 0,6389 \\
\hline
\end{tabular}

Source : Figure 4 (Data Processed)

From the data contained in table 7 , it can be seen that the value of the Prob. Chi-Square of 0,6389 is greater than the value of $\alpha=0,05$; so that it can be stated that the ARIMA $(8,0,6)$ - EGARCH $(1,1)$ model is free from the ARCH Effect. The results of the NASDAQ index value and Return forecast for the next 20 months are as follows:

Table 8. Result Forecasting Value of NASDAQ

\begin{tabular}{|clcc|}
\hline No. & \multicolumn{1}{c}{ Month } & $\begin{array}{c}\text { Forecasting Value } \\
\text { NASDAQ Index } \\
\text { (USD \$) }\end{array}$ & $\begin{array}{c}\text { Forecasting Value } \\
\text { Return NASDAQ (\%) }\end{array}$ \\
1 & August 2019 & 7.700 & $-57,34$ \\
2 & Sept 2019 & 7.846 & 154,75 \\
3 & October 2019 & 7.872 & 35,93 \\
4 & Nov 2019 & 8.043 & 182,46 \\
5 & Dec 2019 & 8.068 & 42,50 \\
6 & January 2020 & 8.169 & 121,41 \\
7 & Peb 2020 & 8.141 & $-7,58$ \\
8 & March 2020 & 8.067 & $-52,18$ \\
9 & April 2020 & 8.033 & $-14,85$ \\
10 & May 2020 & 7.947 & $-67,86$ \\
11 & June 2020 & 7.959 & 28,72 \\
12 & July 2020 & 7.876 & $-66,34$ \\
13 & August 2020 & 7.933 & 74,60 \\
\hline
\end{tabular}

Source : Figure 4 (Data Processed) 
The graphs are as follows:

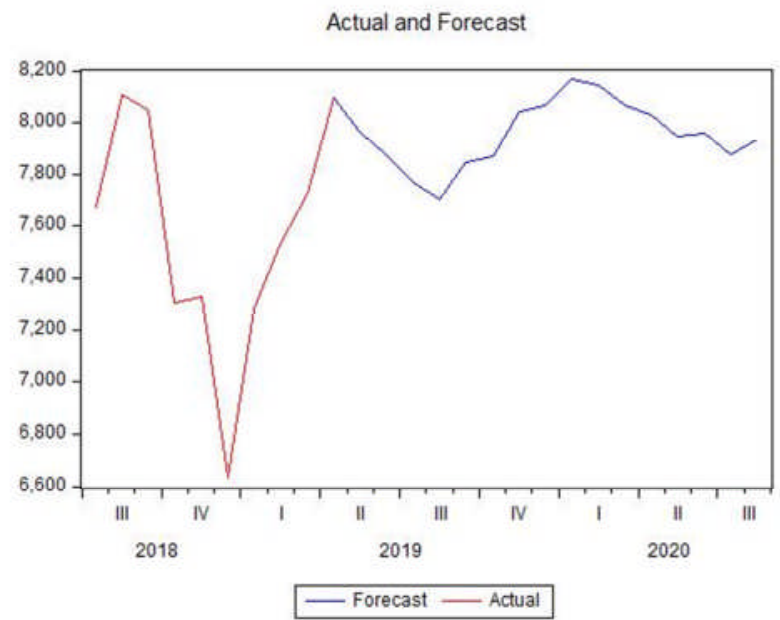

Figure 5. Forecasting Value NASDAQ

Source: Table 8 (Data Processed)

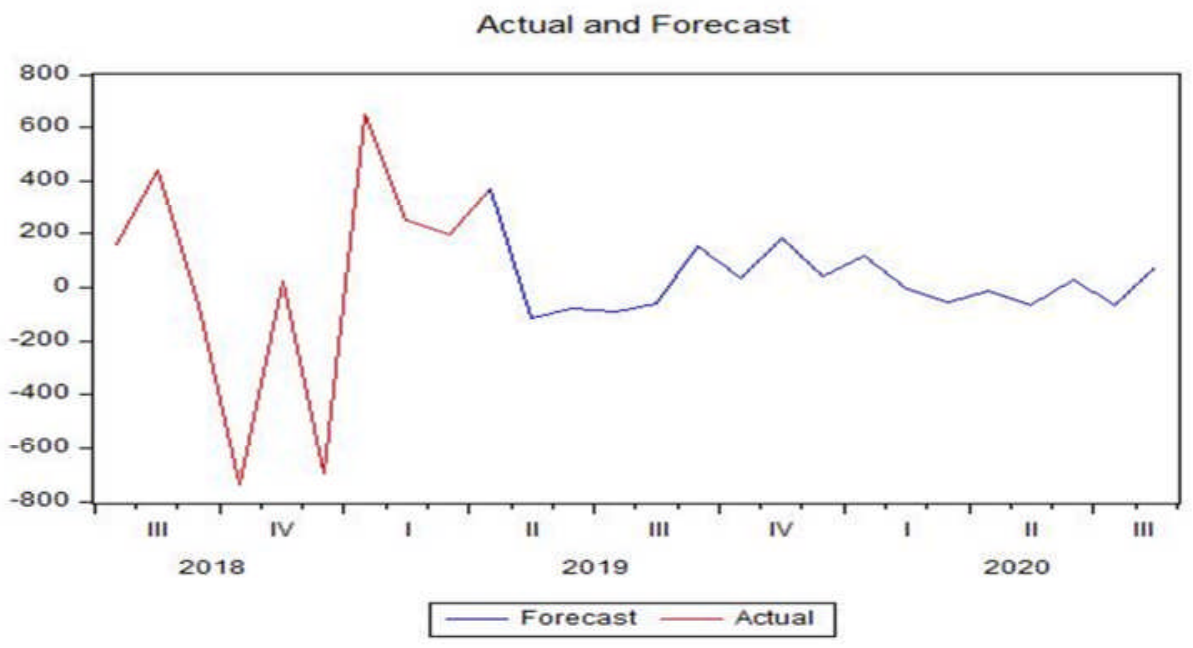

Figure 6. Value of Return NASDAQ

Source: Table 8 (Data Processed)

\section{Discussion}

To predict the movement of stock prices and the level of return that will be obtained can use the analysis of the ARIMA and GARCH models. Before carrying out the ARIMA analysis process, changes in data must first be made or often known as differentiation, which aims to keep data from showing trends. The differentiation is done by finding the return value of the NASDAQ price movement data from 1972 - 2019. From the results of the first test, the results of the non-statementer data are obtained so that the data differentiation process must be carried out. This was also stated by Abounoori, Elmi, \& Nademi (2016), who stated that in order to obtain data that the statisticians had to differentiate the data using the unit root test. From the results of the first test in table 1, get the results of non-statement data. This is indicated from the results of the 
probability of having a value greater than $\alpha=$ 0,05 . Then the results of the second test are $\operatorname{co} \alpha$ ntinued by performing data differentiation, where the data can be seen in table 2, which shows that the data is already a statement or the probability value is greater than the value $\alpha=0,05$. This is in accordance with research conducted by Isida Mansaku and Saimir Mansaku (2016), which performed a one-time differentiation process in turning data into a statement by conducting a unit root test. The next step is to conduct an ACF and PACF analysis which aims to find out which lags can be used to create the ARIMA model. From the results in table 3 , it can be seen that the lag that passes through confidence bounds

After getting the best ARIMA model, it is continued by finding a combination model between the ARIMA and GARCH models, where for the best results, the ARIMA model $(8.0,6)$ - EGARCH $(1.1)$ because it has an AIC value of 10.47331 , this result is certainly different with research conducted by Caporin \& Costola (2019), where the best model in the research is the GARCH model $(1,1)$. After getting the ARIMA $(8,0,6)$ - EGARCH $(1,1)$ model, it is continued by testing the ACF and PACF on the ARIMA $(8,0,6)$ - EGARCH $(1,1)$ model to see whether the probability values obtained are already more than $\alpha=$ 0.05 . From the table 6 data using EViews 10 software, it can be seen that the p-value $>\alpha=$ 0.05 so that it can be stated that the ARIMA $(8.0,6)$-EGARCH $(1.1)$ model is free from AutoCorrelation. This is different from research conducted by David, Ramahatana, Trombe, \& Lauret (2016) where to determine $\mathrm{ACF}$ and PACF by looking at the confidence bounds line, if the lag line crosses the confidence bounds line, it can be stated that the model was detected autocorrelation so that it can be used to make ARIMA model. Next, the ARCH Effect Test is performed on the ARIMA (8.0,6) -EGARCH (1.1) model, where in table 7 the p-value of 0.6396 is greater than the $\alpha$ value of 0.05 . This means that the ARIMA $(8,0,6)$-EGARCH $(1,1)$ model is free from the ARCH Effect, this is in line with several studies conducted by Eliyawati, Hidayat, \& Azizah (2014); Guang, is lags $6,8,10$. This is in accordance with research conducted by Katsiampa (2017), where the results obtained in terms of determining lag are $6,8,10$, so in the research the ARIMA model was chosen using lags 6 , 8 , 10. From table 4 it is known that the ARIMA model $(8.0,6)$ has the smallest AIC value of 12.66 so that the ARIMA model (8.0.6) used as the best model for forecasting both NASDAQ prices and NASDAQ return rates in the future. This is not in accordance with research conducted by Kambouroudis, McMillan, \& Tsakou (2016), where the best ARIMA model results obtained are ARIMA models $(0,1,1)$.

$\mathrm{Yu}$, Xiaoyan, \& Tian (2014) and Hung (2011). For the next stage, theil Inequality Coefficient analysis of the ARIMA $(8.0,6)$ EGARCH $(1,1)$ model is carried out, which gets a result of 0.969278 . For NASDAQ price forecast forecasting results and return rates can be seen in Table 8, where the value fluctuates and is stagnant.

\section{CONCLUSION}

On the NASDAQ Composite Index from March 1971 to April 2019 it appears that the data is not stationary. For this reason, differentiation is needed by finding the value of stock returns from the NASDAQ Composite Index data from March 1971 to April 2019. After differentiating by looking for return values, the next analysis can be done, namely looking for the ARIMA model. Finding an ARIMA model using conventional analysis will require a long analysis time. So to shorten the analysis process using the EViews 10 statistical program. The results obtained after using the EViews program are getting the ARIMA model $(8.0,6)$. The ARIMA model $(8,0,6)$ was chosen because it has the smallest AIC value of 12,664073. This can be used as a reference later that the ARIMA model $(8.0,6)$ is the best model in conducting forecasting. After that, the GARCH model is continued which aims to determine the ARIMA-GARCH model 
combination model. From the results of the analysis, it is known that the best model for forecasting the return value of the NASDAQ Composite Index is a combination of ARIMA $(8.0,6)$-EGARCH $(1,1)$ models, which from

\section{REFERENCE}

Abounoori, E., Elmi, Z., \& Nademi, Y. (2016). Forecasting Tehran stock exchange volatility; Markov switching GARCH approach. Physica A: Statistical Mechanics and Its Applications, 445, 264-282. https://doi.org/10.1016/j.physa.2015.10. 024

Alemohammad, N., Rezakhah, S., \& Alizadeh, S. H. (2018). Markov switching asymmetric GARCH model: stability and forecasting. Statistical Papers, 1-25. https://doi.org/10.1007/s00362-0180992-2

Bahamonde, N., Torres, S., \& Tudor, C. A. (2018). ARCH model and fractional Brownian motion. Statistics and Probability Letters, 134, 70-78. https://doi.org/10.1016/ j.spl.2017.10.003

Bekaert, G., \& Hoerova, M. (2014). The VIX, the variance premium and stock market volatility. Journal of Econometrics, 183(2), 181-192. https://doi.org/10.1016/J.JECONOM.20 14.05.008

Caporin, M., \& Costola, M. (2019). Asymmetry and leverage in GARCH models: a News Impact Curve perspective. Applied Economics, 0 (0), $1-20$.

https://doi.org/10.1080/00036846.2019. 1578853

Charles, A., \& Darné, O. (2014). Large shocks in the volatility of the Dow Jones Industrial Average index: 1928-2013. Journal of Banking and Finance, 43(1), 188-199.

https://doi.org/10.1016/j.jbankfin.2014.0 3.022

David, M., Ramahatana, F., Trombe, P. J., \& the results of this analysis are known for fluctuating return values and index values for NASDAQ for one year in the future it is stagnant and does not show a trend.

Lauret, P. (2016). Probabilistic forecasting of the solar irradiance with recursive ARMA and GARCH models. Solar Energy, 133, 55-72. https://doi.org/10.1016/j.solener.2016.03 .064

Eliyawati, W. Y., Hidayat, R. R., \& Azizah, D. F. (2014). Penerapan Model GARCH (Generalized Autoregressive Conditional Heteroscedasticity) untuk Menguji Pasar Modal Efisien di Indonesia (Studi pada Harga Penutupan (Closing Price) Indeks Saham LQ 45 Periode 2009-2011). Jurnal Administrasi Bisnis (JAB), 7(2), 1-10.

Gokbulut, R. I., \& Pekkaya, M. (2014). Estimating and Forecasting Volatility of Financial Markets Using Asymmetric GARCH Models: An Application on Turkish Financial Markets. International Journal of Economics and Finance, 6(4), 23-35.

https://doi.org/10.5539/ijef.v6n4p23

Guang, T., Yu, L., Xiaoyan, L., \& Tian, K. (2014). The Development of Market Economy in China. Advances in Management \& Applied Economics, 4(4), 73-99. Retrieved from www.scienpress.com/Upload/AMAE/V ol 4_4_7.pdf

Guesmi, K., \& Fattoum, S. (2014). Return and volatility transmission between oil prices and oil-exporting and oilimporting countries. Economic Modelling, 38, 305-310. https://doi.org/10.1016/j.econmod.2014. 01.022

Hartaty, H., Jasanta, P., \& Harjum, M. (2018). Symmetric And Asymmetric Shock Models Of Stock Return Volatility In. 
International Journal of Civil Engineering and Technology (IJCIET), 9(8), 1034-1047. Retrieved from https://www.researchgate.net/profile/Jas anta_Peranginangin_Peranginangin/publ ication/327365140_Symmetric_and_asy mmetric_shock_models_of_stock_return _volatility_in_Indonesia_stock_exchang e/links/5b8a5533299bf1d5a735d950/Sy mmetric-and-asymmetric-shock-model

Hung, J.-C. (2011). Applying a combined fuzzy systems and GARCH model to adaptively forecast stock market volatility. Applied Soft Computing, 11(5), 3938-3945. https://doi.org/10.1016/J.ASOC.2011.02 .020

Isida Mansaku, Saimir Mansaku, I. T. (2016). An empirical comparison of the major stock exchanges: NYSE, NASDAQ and LSE in Perspective. Academic Journal of Interdisciplinary Studies, 5(3), 406415.

https://doi.org/10.5901/ajis.2016.v5n3s1 p406

Kambouroudis, D. S., McMillan, D. G., \& Tsakou, K. (2016). Forecasting Stock Return Volatility: A Comparison of GARCH, Implied Volatility, and Realized Volatility Models. Journal of Futures Markets, 36(12), 1127-1163. https://doi.org/10.1002/fut.21783

Katsiampa, P. (2017). Volatility estimation for Bitcoin: A comparison of GARCH models. Economics Letters, 158, 3-6. https://doi.org/10.1016/j.econlet.2017.06 .023

Lahmiri, S., \& Boukadoum, M. (2014). An Ensemble System Based on Hybrid EGARCH-ANN with Different Distributional Assumptions to Predict $S \& P 500$ Intraday Volatility. Fluctuation and Noise Letters, 14(01), 1-10. https://doi.org/10.1142/s0219477515500 017

Lin, Z. (2018). Modelling and forecasting the stock market volatility of SSE Composite Index using GARCH models. Future Generation Computer Systems, 79, 960972. https://doi.org/10.1016/j.future.2017.08. 033

Monfared, S. A., \& Enke, D. (2014). Volatility forecasting using a hybrid GJR-GARCH neural network model. Procedia Computer Science, 36, 246253.

https://doi.org/10.1016/j.procs.2014.09.0 87

Neama, N. H. (2016). Accumulated Remark Forecasting for American NASDAQ Stock Market by using Artificial Neural Network Models from 2006-2015. Global Journal of Finance and Management, 8(2), 143-151. Retrieved from

http://www.ripublication.com/gjfm16/gj fmv8n2_04.pdf 